\title{
КАЗАХСТАНСКИЕ ПРЕДПРИЯТИЯ ПЕРЕХОДЯТ НА МСФО
}

\author{
E. М. Бутин (E. M. Butin)
}

\section{Предисловие}

В настоящее время все в большей степени получают признание два глобальных языка финансовой отчетности Международные стандарты финансовой отчетности (International Financial Reporting Standards - IFRS) и Общепринятые принципы бухгалтерского учета США (Generally Accepted Accounting Principles - GAAP). Многие страны при выборе отдают предпочтение МСФО, так как, по свидетельству мировой практики, IFRS все в большей мере признаются достигшими уровня завершенности и точности при подготовке отчетов компаниями по международным стандартам.

В чем же проявляется необходимость и преимущества международной стандартизации бухгалтерского учета, обусловившие их становление и развитие? Выделим основные группы факторов:

- обеспечение потребностей инвесторов;

- облегчение работы транснациональных корпораций;

- совместное использование бухгалтерских знаний.

В текущем году почти все предприятия (за исключением государственных организаций) Республики Казахстан переходят на МСФО. Так, согласно Закону РК [2] определено, казахстанские компании должны составлять финансовую отчетность в соответствии с МСФО:

- для отдельных организаций, определяемых в порядке, установленном Правительством Республики Казахстан, - с 1 января 2003 г.;

- для акционерных обществ - с 1 января 2005 г.;

— для иных организаций - с 1 января 2006 г.

\section{Казахстан}

Как же этот вопрос решается в Казахстане? Отчетность по МСФО станет третьей, а для некоторых предприятий и четвертой системой учета, помимо налогового, бухгалтерского и управленческого учета. По своей сути бухгалтерский учет и финансовая отчетность составлялась отечественными предприятиями, в основном, только для пользователей налоговых органов, и не полно удовлетворялись требования других внешних пользователей. Между тем, согласно МСФО цель составления финансовой отчетности - это представление информации о финансовом положении, результатах деятельности, и изменениях в финансовом поло- жении компании, которая нужна широкому кругу пользователей при принятии экономических решений [3].

Несмотря на определенный опыт казахстанских компаний в ведение учета и подготовки финансовой отчетности в соответствии национальных стандартов бухгалтерского учета, которые были гармонизированы к МСФО, тем не менее, вхождение их в МСФО потребует приложения определенных сил, времени и затрат. Основными препятствиями внедрения МСФО в Казахстане, преодоление которых будет сложным, являются:

1. Главная трудность для практических работников в том, что МСФО определяют общие принципы, подходы к учету и составлению финансовой отчетности, а не детальные процедуры. Они не выдвигают конкретных правил и инструкций, форм первичных документов и учетных регистров. Нет привычного для нашего бухгалтера Типового плана счетов и типовых бухгалтерских проводок. Нет того методического материала, который был привычен прежней системе учета и отчетности. Крайне затруднительно будет практикующим бухгалтерам при составлении финансовой отчетности учитывать такой принцип МСФО, как приоритет экономического содержания над формой.

2. Отсутствие перевода МСФО на государственный и русский языки.

В соответствие статьи 2-1 Закона РК [2] необходимы публикации МСФО одновременно как на казахском, так и на русском языках. Однако, ни русского, ни казахского отечественного перевода на сегодня в РК нет. Между тем, Комитет по международным стандартам финансовой отчетности (КМСФО) категорически запрещает странам, принявшим решение использовать МСФО, править первоначальный текст стандартов.

3. Отражение активов и обязательств по справедливой или рыночной стоимости. В связи с тем, что казахстанские стандарты бухгалтерского учета соответствуют в основном многим положениям МСФО, переклассификация статей баланса в казахстанском бухгалтерском учете будет не так сложна по сравнению, например, с российским бухгалтерским учетом.

4. Технические сложности могут возникнуть при принятии Нового плана счетов. Министерством финансов РК была 
разработана Инструкция (основа) по разработке Рабочего плана счетов бухгалтерского учета, для организаций, составляющих финансовую отчетность в соответствии с международными стандартами финансовой отчетности. Введена в действие с 5 января 2006 года. Инструкция определяет общие требования для предприятий по разработке рабочего плана счетов организаций. Теперь бухгалтеры по своему усмотрению, в зависимости от потребностей, могут варьировать на одних и тех же счетах, те или иные детализированные их виды, что в целом не способствует единообразию в понимание экономической сути бухгалтерских счетов. В то же время, не может быть единого плана счетов для всех предприятий и организаций страны. Однако, новый План счетов разработан в усеченной форме, Так, здесь нет счета брак в производстве, расходы по эксплуатации оборудования, не в полной мере показаны затраты. Более приемлемо было бы вести учет дебиторов и кредиторов на едном синтетическом счете, нет надобности в открытие счетов коммерческих расходов и арендной платы. Одни счета чрезмерно детализированы, например, денежные средства, другие, наоборот, представлены в усеченной форме - «основные средства», что больше соответствует в Плане счетов подразделу, нежели синтетическому счету. Трудно согласиться по объединению на одном счете амортизации и обесценения (сущность которых не адекватна) по: основным средствам, инвестициям в недвижимость, разведочным и оценочным активам, а также нематериальным активам. И таких погрешностей и недостатков предостаточно. Предлагаемый новый План счетов неотработан, предлагаемая модель синтетических счетов весьма громоздка, в ней нет внутреннего единства и взаимозависимости, она и неудобна для восприятия, здесь не учтены возможные ограничения при автоматизации учета.

4. Раскрытие информации о зависимых сторонах, которые в наших условиях, в ряде случаев, получить довольно сложно. Необходимость раскрытия операций между связанными сторонами обусловлена тем, что такие операции могут привести к результатам, отличающимся от результатов операций между несвязанными сторонами.

5. Противоречия с гражданским и налоговым законодательством. Бухгалтерский учет, его терминология, понятия и категории, являются составной частью законодательства, поэтому внедрение МСФО неизбежно повлечет конфликт, так как многие их положения противоречат соответствующим нормам действующего законодательства.

6. Наиболее сложным в составлении финансовой отчетности по МСФО является составление и раскрытие информации консолидированной отчетности. В консолидиро- ванной финансовой отчетности должны быть раскрыты: сущность взаимоотношений между материнской компанией и дочерними предприятиями; доли капитала и доли голосующих акций; описание метода, используемого для учета дочерних компаний.

Дополнительные трудности возникают в связи с отдельными изменениями самих МСФО. Так, в 2004г. Комитет МСФО предпринял ряд дополнений, направленные на большее применение рыночной оценки активов и обязательств, а также на трансформацию стандартов учета с GAAP США.

Как известно, МСФО лишь регламентируют подготовку и составление отчетности, не затрагивая сам процесс учета, что вызывает много вопросов и непониманий среди бухгалтеров. Так, не совсем ясно, как будет регламентироваться сам процесс учета? Кто будет контролировать соответствие отчетности требованиям МСФО? Будут ли отменены ныне действующая система учета и отчетности? Как необходимо составлять рабочий план счетов?

Министерством финансов РК была разработана Инструкция (основа) по разработке рабочего плана счетов бухгалтерского учета для организаций, составляющих финансовую отчетность в соответствии с МСФО [4].

Рекомендуемая Инструкция определяет общие требования по разработке рабочего плана счетов бухгалтерского учета. Рабочий план счетов предусматривает четырехзначную кодификацию синтетических счетов бухгалтерского учета. Первая цифра номера указывает на принадлежность к разделам, вторая - на принадлежность к подразделам, третья - на принадлежность к группам синтетических счетов, четвертый знак не задействован, и оставлен свободным для самостоятельного использования организацией. Счета должны быть представлены по степени убывания ликвидности.

Рабочий план счетов содержит следующие разделы:

1. Раздел - «Краткосрочные активы».

2. Раздел - «Долгосрочные активы».

3. Раздел - «Краткосрочные обязательства».

4. Раздел - «Долгосрочные обязательства».

5. Раздел - «Капитал и резервы».

6. Раздел - «Доходы».

7. Раздел - «Расходы».

8. Раздел - «Счета производственного учета».

Как показывает мировая практика, такой подход характерен для многих западных предприятий.

Многие экономисты ошибочно считают, учетная система в развитых странах запада не регулируются государством, основную роль играют профессиональные бухгалтерские организации. Между тем, это не совсем так. Если обратим- 
ся к опыту развитых зарубежных стран то, видим, что здесь существует как прямое регулирование на уровне государственного управления, так и косвенное посредством мандатного управления.

К прямому регулированию бухгалтерского учета следует отнести организацию учетного процесса Франции, Германии и др. Косвенное регулирование характерно для экономики Великобритании, США и др.

Рассмотрим основные положения регулирования системы учета в этих странах.

В связи с переходом на МСФО казахстанским предприятиям необходимо в первую очередь пересмотреть учетную политику и привести ее в соответствие с требованиями международных стандартов.

Учетная политика по своей структуре и форме изложения состоит из трех блоков:

- общий раздел;

— организационный раздел;

- методический раздел.

В первом разделе необходимо обеспечить соответствие финансовой отчетности компании требованиям всех Международных стандартов финансовой отчетности и Интерпретаций Постоянного комитета по Интерпретациям. Особо следует выделить случаи отступлений от общепринятых допущений при ведении учета и составлении финансовой отчетности, в случаях их допустимости и оправданности, с указанием причин и следствий.

\section{Франция}

Бухгалтерский учет французских компаний регламентируется на государственном уровне. Учет регулируется Торговым кодексом, Законом о производственно-торговых компаниях, Законом о национальных компаниях, Декретом 1967 года за №67/236 и налоговым законодательством.

Учетные стандарты разрабатывает государственный орган Национальный совет по бухгалтерии (Conseil National de la Comptabilité - CNC). Это общественная организация, работающая в тесном взаимодействии с Министерством экономики, финансов и бюджетов. Учетный процесс регламентируется Общим планом ведения бухгалтерии (Plan Comptable General - PCG), принятый 1982 году. Он содержит унифицированный план счетов, стандартные формы бухгалтерской отчетности, инструкции и рекомендации по ее составлению, а также другие методические рекомендации. Общий план ведения бухгалтерии включает следующие разделы: общие принципы; терминология; правила оценки; правила исчисления прибыли и убытков; сводные бухгалтерские документы для различных групп компаний; порядок ведения бухгалтерских документов; ежегодные бухгалтерские документы; расчет себестоимости.

В связи четкой методологической направленностью, План счетов бухгалтерского учета Франции получил широкое распространение во многих странах мира. План счетов основывается на шестизначной системе кодирования счетов, где порядковый номер цифр означают:

1 - класс (раздел) счетов,

2 - счет,

3 - субсчет первого порядка.

4 - субсчет второго порядка,

5 - аналитический счет первого порядка,

6 - аналитический счет второго порядка.

Разделы Плана счетов разделяются на следующие классы:

- балансовые счета (классы1-5);

- счета «затраты-выпуск» (6-7);

- специальные счета (класс 8)

— счета аналитической эксплуатации (класс 9)-счета управленского учета;

- резерв для внутренних потребностей компании (класс $0)$.

Структура французского Плана счетов представлена в таблице 1 [5].

\begin{tabular}{|l|l|}
\hline Классы счетов & \multicolumn{2}{l|}{ Содержание } \\
\hline Финансовый учет & \\
\hline 1 & Капитал \\
\hline 2 & Внеоборотные активы \\
\hline 3 & Запасы и незавершенное производство \\
\hline 4 & Счета к получению и счета к оплате \\
\hline 5 & Финансовые \\
\hline 6 & Расходы \\
\hline 7 & Доходы \\
\hline 8 & Специальные \\
\hline Управленческий учет \\
\hline 9 & $\begin{array}{l}\text { Счета контроля за затратами, группировки и } \\
\text { анализа }\end{array}$ \\
\hline
\end{tabular}

Таблица 1: Структура фрранцузского Плана счетов

\section{Германия}

Регулирование бухгалтерского учета осуществляется Коммерческим кодексом, Законом о балансах, Закона о налоге с оборота, Закона о подоходном налоге и Закона о налоге на корпорации. На основании, выше названых документов, приняты Основные положения по организации бухгалтерского учета. Особенностью организации германского учета является жесткая централизация государственного регулирования и использование двух видов отчетности - коммерческой и налоговой. 
Ранее действовал единый план счетов. В настоящее время в Германии разработаны, рекомендуемые планы счетов для различных отраслей, исходя из их потребностей. Однако, рекомендуемый Перечень счетов может дополняться и изменяться в зависимости от развития компании.

Германские бухгалтерские счета, как и французские, подразделяются на классы, группы и подгруппы. Структура плана счетов Германии представлена в таблице 2 [5].

\begin{tabular}{|l|l|}
\hline Классы счетов & Содержание \\
\hline 0 & Постоянные активы и капитал \\
\hline 1 & Финансовые счета \\
\hline 2 & Доходы и расходы \\
\hline 3 & Материалы \\
\hline 4 & Затраты по элементам \\
\hline $5-6$ & Счета себестоимости \\
\hline $7-8$ & Счета управленческого учета \\
\hline 10 & Счета балансовых остатков \\
\hline
\end{tabular}

Таблица 2: Структура Плана счетов Германии

\section{Великобритания}

Для Великобритании характерным является минимальное государственное регулирование. В основе управления лежит двухуровневая система регулирования учетным процессом. Совет по финансовой отчетности (Financial Reporting Council - FRC) осуществляет общее управление учетной политикой и утверждение стандартов. Разработкой самих стандартов, основных методологических документов, регулирующие ведение учета, выявления несоответствия финансовой отчетности стандартам осуществляются Советом по стандартам бухгалтерского учета (Accounting Standard Board - ASB), Оперативной рабочей группой (Urgent Issue Task Force - UITF), Экспертной группой по анализу финансовой отчетности (Financial Reporting Review Panel - FRRP) и Консультативным комитетом бухгалтерских организаций (Consultative Committee of Accounting Bodies - CCAB).

\section{США}

Разработкой национальной системой бухгалтерского учета и ее регулированием в США занимаются следующие уполномоченные организации:

\section{1. Государственные органы.}

- Комиссия по ценным бумагам и биржевым операциям (Securities and Exchange Commission -SEC);

- Правительственное управление бухгалтерских стандартов для государственных организаций (Governmental Accounting Standards Board - GASB).

\section{2. Профессиональные бухгалтерские организации.}

- Американский институт присяжных бухгалтеров (American Institute of Certified Public Accountants AICPA);

- Комитет по стандартам финансового учета (Financial Accounting Standards Board - FASB);

- Национальная ассоциация бухгалтеров (National Association of Accountants - NAA);

- Американская бухгалтерская ассоциация (American Accounting Association - AAA);

- Институт управленческих бухгалтеров (Institute of Management Accountants - IMA).

Кроме вышеназванных организаций в США существуют и другие органы, которые оказывают определенное влияние на формирование учетной политики, методы учета и разработку стандартов. К ним относятся: Институт финансовых руководителей, государственный департамент по снабжению и налогам и др.

GAAP объединяют правила и процедуры, регулирующие принятую практику учета в определенное время. Документы GAAP разделяются на четыре категории (уровни) от обязательных, до рекомендательных [6].

В регулирование учета преобладает косвенное государственное управление. Основную роль в разработке GAAP в США играют профессиональные бухгалтерские организации, в целом, и FASB, в частности. Однако, при этом следует учесть, что эти полномочия FASB получила от государственной Комиссия по ценным бумагам и биржевым операциям, образованного Конгрессом США. Следовательно, роль государственного регулирования осуществляется через мандатную форму управления, то есть посредством предоставления полномочий определенным организациям от своего имени.

Бухгалтерские счета в США подразделяются на основные, неизменно присутствующие в учетном процессе, и эпизодические, которые используются в нетипичных, разовых операциях. В США отсутствует единый План счетов (Chart of Accounts), каждая компания, исходя из специфики деятельности, сама определяет свой План счетов бухгалтерского учета. Однако, формируемые в компаниях Планы счетов отражают влияние стандартов учета, требования которых сформулированы международными и профессиональными бухгалтерскими организациями.

План счетов разрабатывается на основе общей классификации счетов, которая, в свою очередь, опирается на пять основных элементов финансовой отчетности: активы, обязательства, собственный капитал, доходы и расходы. Поэтому, План счетов компаний содержит, как минимум эти пять основных элементов. Однако, наряду с этими счетами 
отдельные предприятия используют такие специфические счета, как оценочные (valuation accounting), которые регулируют оценку отдельных активов, обязательств и капитала. Например, резерв по сомнительным долгам, величина дисконта по выпущенным облигациям, которые служат регулирующими статьями, соответственно для дебиторской задолженности и обязательств по облигациям. Оценочные статьи (счета) не входят в группу счетов, они корректируют стоимостную оценку соответствующих статей. Если оценочные счета увеличивают стоимость соответствующих статей, они называются добавочными (adjunct accounts), а если уменьшают стоимость, - контрсчетами (contra accounts). Добавочные и контрсчета, как правило, отражаются в балансе после тех статей, которые они регулируют. Однако имеют место, когда оценочные счета имеют свою собственную нумерацию. Впрочем, самостоятельно могут нумероваться и различные виды активов, обязательств, собственного капитала, доходов и расходов. Иначе говоря, для компаний США степень детализаций счетов, их названий и нумераций весьма индивидуальны.

Перечень (совокупность) всех счетов, используемых на предприятиях США, приводится на первой странице Главной книги (General Ledger), и представляет собой План счетов данной организации. Нумерация счетов у каждого предприятия индивидуальна, которая группируется по определенной системе. Например, профессиональный план счетов одной из компаний США имеет следующую нумерацию счетов: счета активов начинаются на 0001, счета обязательств - на 1000 , счета собственного капитала - на 2000 , продажи (счета доходов) - на 3000, административные затраты (счета расходов) - на 5000, счета неоперационные доходы и расходы - на 5040 [7].

Более того, в США нет единых, обязательных отчетных форм. Бухгалтерский баланс и отчет о прибылях и убытках американских компаний отличается большей компактностью и аналитичностью по сравнению с нашими аналогичными формами отчетности. Главные требования, предъявляемое к отчетности США, - понятность (understandability) и полезность для принятия решений (decision usefulness) информации для различных групп пользователей. В американской системе учета, в отличие от международных стандартов, нет единого документа, определяющего общие правила представления информации в финансовой отчетности. Среди разнообразных форм финансовой отчетност можно выделить:

- баланс;

- отчет о прибылях и убытках и совокупном доходе (последний отчет может представляться как самостоятельный отчет, объединяться с отчетом о прибылях и убытках или с отчетом об изменениях в собственном капитале); - отчет об изменениях собственного капитала (в том числе может включать инвестиции и изъятия собственников);

- отчет о нераспределенной прибыли (может представляться как самостоятельный отчет или объединяться с отчетом о прибылях и убытках, или включаться в отчет об изменениях в собственном капитале);

च отчет о движении денежных средств;

- пояснения к данным отчетам.

Для обеспечения пользователей полезной информацией финансовые отчеты американских предприятий содержат сравнимую информацию за периоды, предшествующие отчетному. Баланс, принято представлять за два года (отчетный и предшествующий), а другие отчеты - за три года (отчетный и два предшествующих).

Наши отечественные предприятия, в соответствии с Приказом Министерства финансов РК № 427 от 22 декабря 2005 года [4] обязаны наполнять финансовые отчеты за периоды: бухгалтерский баланс - на начало и конец отчетного периода, а все остальные отчеты - за два года (отчетный и предыдущий).

\section{Заключение}

Таким образом, в заключение можно сделать следующие выводы:

Переход отечественных предприятий на МСФО сложный и длительный процесс. Как показывает мировой опыт, ни одна промышленно- развитая страна в мире не использует МСФО полностью как национальные стандарты. Как правило, схожи общие принципы национального учета и МСФО, однако зачастую системы учета имеют значительные отличия. Поэтому, нашему отечественному учету необходимо, используя международный опыт стандартизации учетного процесса и отчетности, стремиться к национальному наполнению системы бухгалтерского учета, творчески переработав тот богатый методологический опыт, который мы имели и имеем.

Думается, что вполне логичным и более предпочтительным было бы создание, на первых порах, управление учетным процессом на уровне государственных органов, с постепенным переходом к двух уровневой системы регулирования: государственных органов и профессиональных бухгалтерских организаций.

К государственным регулирующим органам Республики Казакстан следует отнести Министерство финансов РК, Агентство РК по статистике и Национальный банк РК. К профессиональным бухгалтерским организациям - Палату аудиторов РК, Институт профессиональных бухгалтеров Казахстана, Ассоциация бухгалтеров и аудиторов и др. 
Естественно переход на МСФО потребует новых знаний как у специалистов компаний (бухгалтера, экономисты, юристы, производственники и др.), так и у всех других заинтересованных лиц.

\section{Литература}

[1] Комитет по Международным Стандартам Финансовой Отчетности Разъяснения Международных Стандартов Финансовой Отчетности. ЮСАИД 2001.

[2] Закон РК «О бухгалтерском учете и финансовой отчетности» (с изменениями и дополнениями от 11.06.2004 г. №562-II)

[3] International Accounting Standards 2002. - IASCF, 2002.-P.F-6.

[4] Бюллетень бухгалтера / №3 январь 2006.

[5] Хаханова Н.Н. Международные стандарты финансовой отчетности: Учебное пособие. Серия «Экономика и управление».- Ростов н/Д: Издательский центр «МарТ», 2002.c.23-24.

[6] Wiley GAAP 2002. Interpretation and Application of Generally Accepted Accounting Principles 2002/ P.R. Delaney, B.J. Epstein, R. Nach, S.W. Budak.-John Wiley\&Sons, Inc., 2001.- P.2-4.

[7] Малькова Т.Н. Теория и практика международного бухгалтерского учета: Уч. пособие.- СПб.: Издательский дом «Бизнес - пресса», 2001.

\section{Е.М.Бутин, к.э.н., доцент}

\section{Dr. oec. E. M. Butin}

Академия Баанковского Дела

г. Алматы

Dozent der Akademie für Bankwesen

der Stadt Almaty 
